This item was submitted to Loughborough's Institutional Repository (https://dspace.lboro.ac.uk/) by the author and is made available under the following Creative Commons Licence conditions.

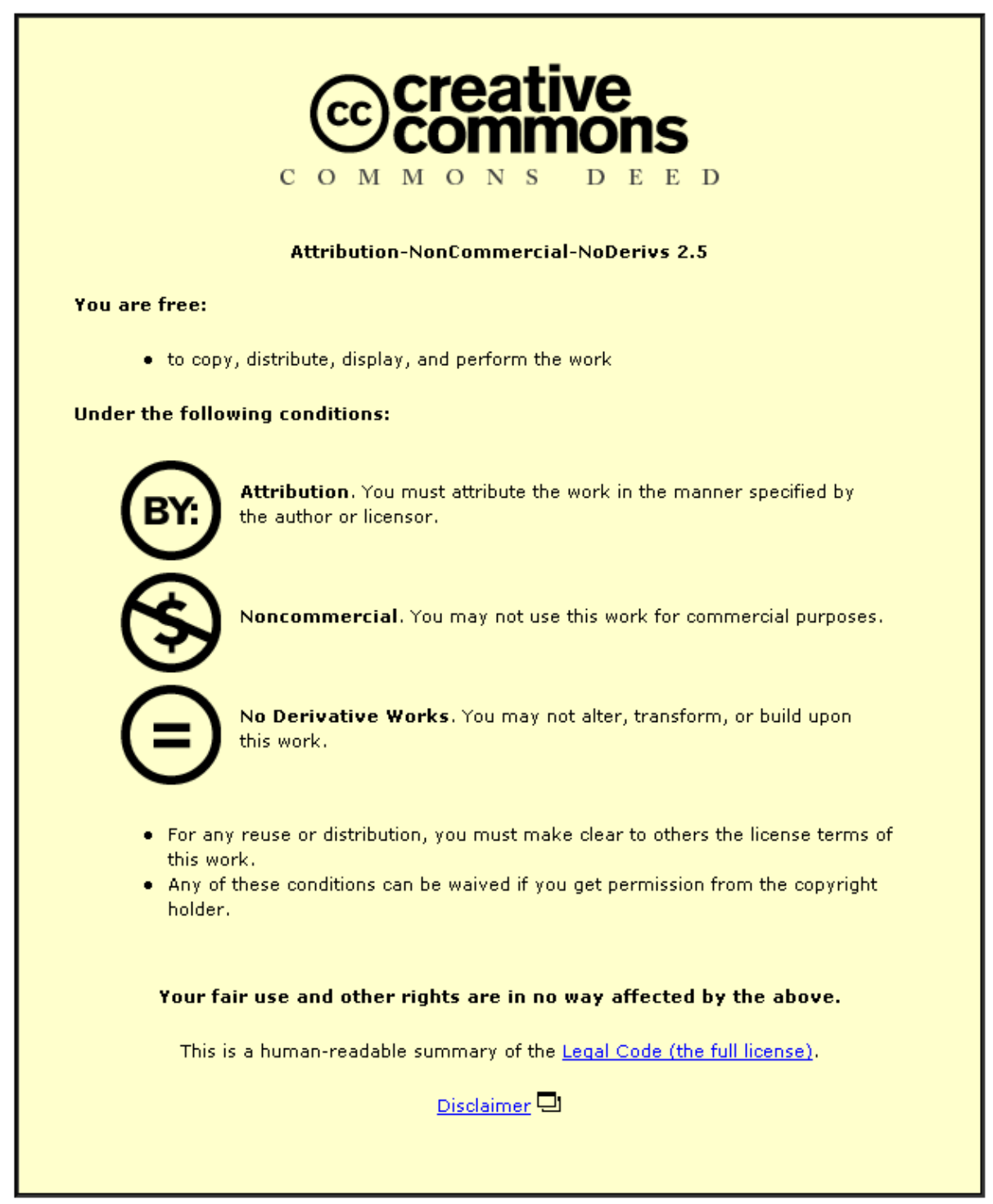

For the full text of this licence, please go to: http://creativecommons.org/licenses/by-nc-nd/2.5/ 
Proceedings of CIB W078 26th International Conference, Managing IT in Construction, 1-3 October 2009, Istanbul Technical University, Istanbul, Turkey. pp 249 - 256

\title{
BPM-driven Construction Client Requirements Change Management
}

\author{
A.K. Jallow, P. Demian \& A.N. Baldwin \\ Civil and Building Engineering Department, Loughborough University, LE11 3TU, UK \\ C.J. Anumba \\ Department of Architectural Engineering, The Pennsylvania State University, PA16802, USA
}

\begin{abstract}
Changing client requirements is one of the principal factors that contribute to delays and budget overruns of construction projects which as a result causes claims, disputes and client dissatisfaction. Change management ensures that such changes are handled through a properly coordinated and controlled process and retained throughout the project life cycle. This paper presents an empirical study that investigated the potential for an automated process of managing changes to clients' requirements in construction projects. An initial focus group meeting was set up as a preliminary study which was followed by two case studies. Participant observation was used to conduct the case studies during which technical documents were also reviewed. The results show that current requirements change management process lacks efficiency. The paper concludes that business process management (BPM) approach could be a solution to better manage the requirements change process.
\end{abstract}

Key words: client requirements, change management, business process management, construction projects, traceability

\section{INTRODUCTION}

Client requirements are initially defined and elicited in the early stages of a project but clients constantly review and change the requirements of their facilities. The documented brief therefore needs to be modified. It then becomes vital to trace the changes, describe and follow the life of the requirements, including changes effected on them. Traceability is therefore a key part of good requirements management. Lack of adequately managing requirement changes contributes adversely to construction budget and schedule overruns. Similarly, Shiau and Wee (2008) claim that delays in product developments are common due to continuous changes in design projects and Nadia et al. (2006) also claim that many of these changes are from customers as emerging requirements or as variations.

Within the construction industry, the current paper-based system used to manage and process requirement changes lacks efficiency. This is fuelled by the number of people involved in the process and the iterations a change request goes through before approval. Inefficient visibility and lack of version update with all stakeholders and at all locations are also contributing factors. Delays are caused in approving the changes as a result of poor communication and coordination of the changes process between stakeholders. A BPM approach could be a solution to this problem to better organise and manage the change process.

The key contribution of this paper is to present a theoretical groundwork of an integrated business process management and web database system to enable efficient client requirements change management. It follows up to the earlier work of Kamara et al. (2002) and Kamara and Anumba (2000) on capturing client requirements and processing in construction projects.

\section{METHODOLOGY}

This paper presents an empirical study of the potential for an automated process of managing changes to clients' requirements in construction projects. The study begins with a review of academic literature particularly, how change is initiated and communicated through the request and authorisation process 
as well as tools available to facilitate this process was studied. This review also includes examples from industries other than construction.

Various research methods were employed. Firstly, an initial focus group meeting was set up as a preliminary study with participants comprising a small number of industry experts from a multinational engineering consultancy firm which specialises in project management. The focus group also included an experienced academic to help share an academic research viewpoint of the problem.

An appreciation of the problem emerged together with the realisation that further observation was needed to understand the problem and propose a solution. Therefore, the subsequent phase of the research was to conduct a case study of construction projects in order to understand some of the issues raised from the focus group meeting.

Two ongoing public building projects were selected. Both had budgets in excess of twenty million Great Britain Pounds. These two projects provided interesting and contrasting examples of client/user requirements. The first building will be occupied solely by the client organisation; the second will be leased by the client to a number of different business organisations whose requirements were known to the client from the outset of the design.

Participant observations were used to conduct the case studies and different project management meetings were attended including periodical progress meetings, design team meetings which include project managers, external consultants, client representatives, design engineers and mechanical engineers. Audio recording of the proceedings were taken as well as hand written notes. After each meeting, informal interviews were conducted with individuals to provide further information in areas which were not understood.

The data collected was transcribed soon after the meetings. Thematic analysis method was used for the analysis (Swenden, 2006; Boyatzis, 1998). During the case studies, documents relating to requirements management such as requirements/ brief documents and change request pro-forma were reviewed.

\section{RELATED WORK}

\subsection{Requirement changes}

The reality of change is inevitable. "In reality, both humans and systems capital will be constantly changing and evolving, and consequently the potential value is likely to be continually changing and dynamic in nature” (Taylor, 2007). Client require- ments define project goals and expectations which are then used to put together the processes, structures, project procurement and contractual agreements necessary to execute the project. In new product development, Requirements Change occurs at each phase of a project through to operation and use. A change in the requirements defined in the brief will have an impact on design, construction, operations and demolition. About half of design defects are caused by changes which includes changes in requirements, specifications and design documents changes which are common in construction projects after contract is awarded (Andi and Minato, 2003; Karim and Adeli, 1999; Shiau and Wee, 2008). There is therefore the demand to manage these changes for visibility, traceability and auditability which facilitates good requirements management.

\subsection{Change dependency and impact}

Every system whether it biological, organisational, social, and technological or a mechanical product is made up of different components that enables the whole to function. A change in one component without a corresponding update on the other may result in malfunction of the whole system. Similarly in construction, a facility is constructed from a set of client requirements. Each of these requirements could have related sub-requirements that are linked to each other. It is important to understand causes of changes and how one change factor relates to another (Motawa et al., 2007). Emmitt (2007) identified that changes need to be checked against critical documents such as the project brief before implementation. This is a slow process since changes have implications for other interconnected aspects of the building. Currently, dependency checking and analysis is manual and time consuming. This is because of the traditional paper base of documenting requirements which requires manual efforts to check those dependences. However, some advances have been made to document and store change requirements in databases but there is a lack of coordination between the formal change process and dependency checking thus lacking efficiency.

\subsection{Managing requirement changes}

Many researchers in Architecture, Engineering and Construction (AEC) have worked on managing change but most of these are centred around design changes or organisational/project changes (Hegazy et al., 2001). There is a clear need to effectively manage the requirement change process as a business process base activity and making sure change information is communicated and updated to a central repository for consistency. Charoenngam et al. (2003) presented a web-based application for managing change orders in construction projects. How- 
Proceedings of CIB W078 26th International Conference, Managing IT in Construction, 1-3 October 2009, Istanbul Technical University, Istanbul, Turkey. pp 249 - 256

ever, this application is generic to project changes and not specifically client requirements. Little attention has been concentrated on managing changes to client requirements which are the source for design and hold the rationale of each design parameter. Thus understanding, documenting and managing requirement changes effectively would facilitate not only proper design change management but any other requirements related changes within and during a project life cycle (Hegazy et al., 2001). Change information includes what requirement was changed, who changed it and the rationale behind the change, what time was it changed, and the dependent requirement(s) affected by the change if any. Such information could provide visibility on the requirement changes by showing the life cycle state of the change within the process. Requirement or any types of changes should be communicated to all parties at the right time so that each member can react to a change accordingly (Sinha et al., 2006).

This paper argues that despite most research dedicated to design changes which resulted in document management systems using shared centralised drive or folder on which project documents are uploaded and notifications sent (Dustdar, 2005), research on requirements change management taking a datacentric approach should be the driving force. Similar thoughts have been expressed by Chassiakos and Sakellaropouls (2008). As changes to requirements often require a chain of processes, effective process control is a catalyst to enable visibility and auditability as well as proper flow of information between all stakeholders. Clients who often request changes to their requirements could access the change system to make their request. Future computer based change control systems will become even more efficient (Kidd and Thompson, 2000). Synchronous and Asynchronous communication and information sharing amongst construction teams is common and have received a lot of attention and resulted in the application of project extranets (Emmitt, 2007; Wilkinson, 2005).

Haymaker et al. (2006) discussed that "Many researchers have observed current practice's difficulty integrating information and processes, or developed systems to help manage this integration". An example is integration between requirements information and design information. "Integrating the change management system with the requirements repository will help satisfy user demands for interoperability" (Jallow et al., 2008). There are several authored standards and best practice for engineering change management both in manufacturing and construction such as Configuration Management II, best practice guide in managing project changes, Change Management Process etc (Yan et al., 2008; Lazarus and Clifton, 2001; Sun et al., 2004) but none has specifi- cally defined how to manage changes relating to client requirements.

\subsection{Business process management systems}

Business processes have several definitions by different schools of thought. However, a generalist definition is that they are a set of organisational activities performed by people and/or machines to delivery business goals or customer/clients needs (Davenport, 1993; Georgakopoulos et al., 1995; Houck, 2007; Kirchmer, 2009; Taylor, 2007).

Business activities are performed as a workflow and recent trends for efficiency and agility driven by competitiveness has resulted in the automation of business processes. These work activities are sometimes referred to as 'tasks' and require interaction with other subsystems. Traditionally, workflow management systems (WfMS) automate the flow of activities (Khalaf et al., 2006). However, Georgakopoulos et al. (1995) identified limitations of WfMS capability to support integration between different systems for interoperability and cannot support enterprise-wide workflow applications effectively. WfMS are static and inflexible in terms of how they perform automation. They have a complex rule base and offer no simulation of processes.

Advances in technology show the introduction of business process management systems (BPM). Various definitions have been coined to mean BPM as integrated set of methods, resources, tools and technologies used to model, design, deploy, execute, simulate and analyse, coordinate and control operational business processes between people, systems and both and can support application integration using web-services-base integration (Garimella et al., 2008; Tanrikorur, 2007). Business processes rely on information as input which is processed to deliver output. BPM facilitates effectiveness, agility and transparency which are crucial in situations where visibility of processes is required for audit purposes. They can also provide real-time monitoring of processes vital to enhance performance and productivity and contributes to better coordination between people and the information they handle. In today's business environment, business processes keep changing as a result of client or customer demands and is a key driver for applying BPM oriented approach in managing changes (Kirchmer, 2009). Web services enable the access and utilising of software services with the use of the internet. Such software services are developed with a Service Oriented Architecture (SOA) philosophy which argues that software can be developed as a service and can be reused by different applications independent of any Information Technology (IT) architecture. "Web services act as data transfer agents and therefore can 
be sequenced into complicated business processes" (Sabri et al., 2007). Anumba and Ruikar (2008) highlight that "The advantage of using web services in a construction context is to efficiently communicate the relevant information and knowledge representations fast, regardless of time and geographical location constraints and in a reliable format”. SOAbased IT environment supports inter-organisational processes. They enable integration and results in internet based processes that are often called ebusiness processes. The organisations integration must be organised through an appropriate BPM approach (Kirchmer, 2009).

\section{CASE STUDY}

\subsection{Results from the initial focus group meeting}

The meeting started with a brief outline on how requirements are documented to enable storage and retrieval; communication and distribution between all project stakeholders; how changes are managed and dependency analysed. Issues surrounding traceability, visibility and auditability were also outlined.

The experts confirmed the importance of requirements management and outlined their current methods to ensure that client requirements were identified at the briefing stage of the project and any changes to these requirements monitored throughout the project. It was identified that in all their projects, details of requirements were included within the project execution plan. Changes to requirements were monitored through change control procedures, where changes are identified and recorded together with the cost and time implications. Other approaches, such as 'Value Management' were used to evaluate potential changes.

To record changes, common platforms of software packages such as Microsoft Word, Email, Excel (especially for costing) are used. A risk register where changes are forwarded and monitored is also maintained. It was however, observed that how changes are managed depends on the type of project employed and clients have preferences to what tools or system to be used; sometimes they are not ready to pay for such systems.

Recognition was made to the fact that any particular requirements system that may be suggested should take in consideration of project management protocols such as the Process Protocol and RIBA Plan of Work. The experts believed that web based tools provided good facilities for managing requirements and represented the future platform for software based systems. Depending on client requirements, it was sometimes necessary to use a particular project management protocol.

\subsection{Change management process}

In the two projects observed, one is at design stage and the other, in construction stage with six months left on the contract. Any member of the project can request a change by filling in a request for change (RFC) form which is then submitted to the consultant company for review. A master RFC number is allocated to the request and issued to client and project manager.

Changes requested to any of the requirements need to be evaluated to understand cost and programme implications. The request is reviewed for cost and time implications. This review would demand design information from the design team who check for all possible impact on the design. This information is collated and sent to the client for approval or otherwise. The Client would also request design information before making any decisions. If suitable, then approval would be made, else, more information or other options would be requested. The request would be declined totally if client doesn't want to go ahead with that change. Information on the approved changes would be sent to the change initiator and to all those that the change may affect. No matter the implications of the change, all changes will have to get client approval before any implementation is made. Often, changes are requested by the client telephoning the consultant project manager who collates the information on the RFC form for the process to begin. Sometimes, the client fills the form instead. Whichever way, the change request still follows the same process.

\subsection{Storing and communicating changes}

The brief document was stored as a text document and electronically archived on compact discs. Printouts are made and hard copies stored in office filling cabinets. Other electronic versions such as portable document format (PDF) are also generated from the text document. The projects observed did not use project extranets to communicate documents, however sometimes a dedicated website is used to upload high volume documents such as drawings for the team to access.

Email was the primary tool used in communicating change request and its related information. This involved a change requester filling in the request for change form and attaching it to an email. The recipient would download the attached form, print and process the request. The form will then be photocopied and distributed as hard copies to the different people who require action on the change. Sometimes, the form is scanned electronically and sent to all parties as email attachment. The design team upon receipt of the change notification and approval effect the change on the design by revising the drawing and attach the new drawings along with the 
change request form because drawings are also primarily used to communicate changes. Telephone and interpersonal communication are other methods and tools used to communicate requirements changes but often it is always required to send a written documentation to that effect. Project meetings were other forms of communicating changes. Many change decisions were made during such meetings regarding client requirements.

\section{ANALYSIS}

\subsection{Documenting, storing and accessing requirements}

A typical major problem is how to efficiently manage client requirement changes so that each member of the team is accessing the most up-to-date version of the requirements and to manage the change process so that requirement changes are updated in real time. Requirements were not always clear to all members of the projects. In many occasions, further clarification was requested on particular requirements and the client project manager had to answer to those or refer back to the client users for clarification. This caused some delay in terms of decision making and programme progress. A particularly interesting episode occurred relating to requirements around the maximum occupancy of the building. This was not made clear in the brief and the design did not reflect the actual number. Further instructions and clarifications had to be made resulting in changes to the drawings. Requirements for data point access were defined in the brief but their exact locations were not. IT personnel from the institution had to be consulted to define the locations for these data access points.

A satellite mounting point was also specified but where on the building this needed to be fixed was not defined. Sometimes, original client requirements are changed during the meetings as a result of design, material acquisition and or health and safety issues. There are situations when people cannot remember the rationales behind some of the decisions made which resulted to a change in requirements. Recording what decisions were made during such changes is also an important factor for requirements change management.

\subsection{Communicating and updating requirement changes}

It was clear that most of the changes discussed during these meetings were not made known to all the members prior to the meetings. It was however observed that in some cases, the meeting would not progress on certain matters as the relevant documents were not available or some of the attendees would claim to not have received such documents. In a particular scenario, an attendee claimed to have received an email on design related changes but did not see the attached document whilst others received the attachment. Telephone conversations are barely recorded and make it difficult to trace change decisions. Because clients do not always define clearly their requirements in some situations on certain components of the building, the design team assumed what is best or required by the client. Such decisions become new and emerging requirements that also need to be relayed back to the requirements or brief documents. An incident occurred when the RIBA Stage $C$ design report had differences with the Stage C M\&E report regarding fire safety procedures. As a result, all the advice given by the M\&E report was revised. The representative had to call his office for clarification on this point before the meeting could progress. This shows that different versions of a requirement could be located at different places and used by different teams on different part of the project.

\subsection{Way forward}

Clearly defining requirements is crucial but their management, especially making sure there is a centralised dedicated repository, is the best way forward. Such a repository should be accessible to all those involved in the project with access rights. It was observed that requirements and their changes are communicated within a complex interaction between multiple clients who are based in different geographical locations having different stake in the project. Establishing a robust change management mechanism supported by reliable and dynamic technology could be a catalyst to good requirements change management.

\section{PROPOSED CLIENT REQUIREMENTS CHANGE MANAGEMENT SYSTEM}

The proposed system is composed of two main components (1) a requirements information repository and (2) a business process management application.

\subsection{Requirements information repository}

A centralised database application is proposed to serve as a repository to store all client requirements. This is expected to be supported by industry best practice to document and store the requirements once the initial brief has been collated. Because briefing is regarded as a continuous process 
throughout a construction process, new requirements will be borne which could also be added to the repository. Changes which could include additions (new requirements), deletions or amendments (as a result of variations), could also be processed within the repository. As a result, it is necessary for different stakeholders to access up-to-date information through the repository from different geographical locations.

Thus, a web database system is the proposed technology for the repository. The database is able to hold initial requirements and also information on changes to those defined requirements. The changes would trigger an update to the requirements without deleting the initial ones.

\subsection{Business Process Management Application for Change Process Management}

The construction industry is known to be a process based industry and it is thus necessary to implement systems that will help coordinate and control the processes. Changes within requirements is one of those processes that require proper control and coordination amongst all parties as it involves transfer of information and documents between people and across geographical locations. In order to realise an efficient and effective change management, a business process application is proposed to facilitate this process. This application is expected to be integrated with the requirements repository.

The business process management application will be developed using commercial or open source BPM software. A form will be used at the start of a change process where a change initiator fills in all the necessary information. This form will then be routed through the process. All actions on the form will be recorded at each stage of the process including - time of arrival and departure, information added or deleted, who took action etc. Once the process is completed, one can revisit that job instance to review the history (all that has taken place) during that process.

The visibility is crucial in case there is delay with the process as one can easily review and know where exactly the process is 'lying dead'. Figure 1 shows a conceptual representation of the proposed system.

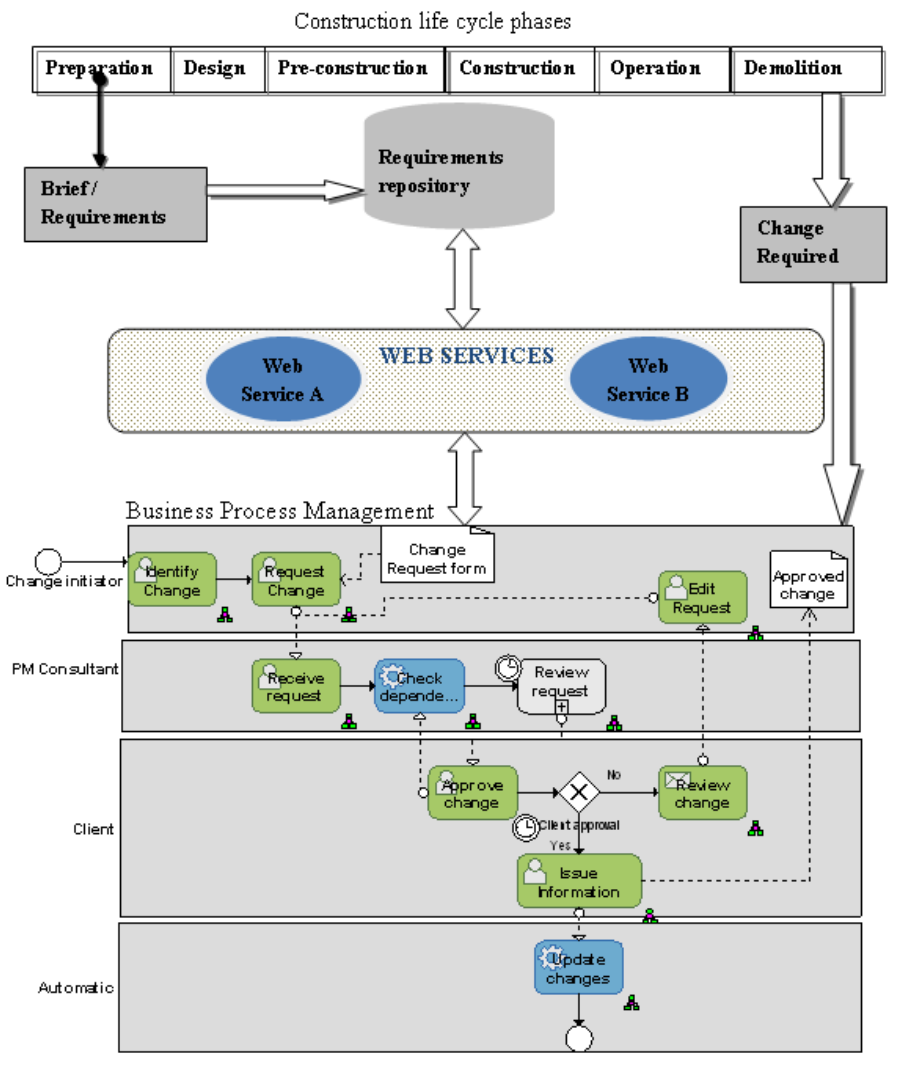

Figure 1: Proposed requirements change management system

The application will provide the functionality of calling services of external systems (the requirements repository) using web services at activities when this would be needed. Such activities would be: (i) Checking for dependency and (ii) Updating requirements and or adding new ones as a result of a change. Two web services would be: (i) Web service A (Dependency Checker) and (ii) Web Service B (Requirement Updater)

\subsubsection{Web Service A - Dependency Checker}

This is a service invoked from the database within the BPM application just before an authorised person 'approves' a change request. This is shown on the change process as 'check dependency' and is an automatic activity. It enables the authorising agent to check dependency of the requirement to be changed with other requirements in the database. This will facilitate and enhance evaluation of the change and the impact to be analysed as the dependency checker will reveal if any other requirement will be affected if the change is implemented. Once the service is consumed and dependency check completed, the process continues to the next activity without the user realising if an external system has been utilised. Without this web service, the authorising person would need to invoke the database system separate from the process management system to check for this dependency.

Similarly, without a requirements database which takes a data-centric approach, the process would have requested paper documents to be reviewed to 
Proceedings of CIB W078 26th International Conference, Managing IT in Construction, 1-3 October 2009, Istanbul Technical University, Istanbul, Turkey. pp 249 - 256

check for any dependency. This could be cumbersome, manual and time consuming. In some cases, no dependency would be noticed because of the inefficiency of going through large documents similar to document centric systems as in extranets.

\subsubsection{Web service B - Requirement Updater}

This is a service invoked from the database within the BPM application immediately after a change is 'approved'. This is shown on the change process as 'Update changes' and is an automatic activity. It enables the changing requirement to be updated real time with the most recent information in the change request. Without this service, a user would have to manually input the changes to update the requirement in the database.

In some cases, no immediate update is made if manual process was used thus creating delay in updating information. Consequences of this are data inconsistency and invalidity in that a superseded requirement would still be in the database which could be made use of by other people. In a manual paperbased system of requirements change management, having to update this change is virtually impossible on all instances of the original requirement as different instances would be located on different places. Depending on the requirement that is changed and updated, a notification will be sent via email to all those who may be affected by the changes.

\section{DISCUSSION AND CONCLUSION}

Requirements change management is recognised as a difficult task because of the many number of people involved, the iteration a change goes through as well as the manual paper work involved. There is need to use information systems to help in the coordination and collaboration during requirements change management. Although some systems have been developed or proposed to handle this process they are generally centred on design change management and are not data-centric. In some cases, databases are used to store requirements but these often lack integration between such systems and change management systems.

A BPM driven requirements change management is proposed to facilitate a much more efficient, dynamic, agile and transparent process management and integration with requirements repository. This will enhance a robust mechanism of requirements change management and at the same time making sure key concerns of requirement change management are met. The next steps planned for this research are to prototype the proposed system and then to evaluate this prototype. This would help to validate the theoretical principles upon which the prototype has been developed: requirements repository, integrated with other systems, BPM for change management system.

\section{REFERENCES}

Andi. \& Minato, T. 2003, "Design documents quality in the Japanese construction industry: factors influencing and impacts on construction process", International Journal of Project Management, vol. 21, no. 7, pp. 537-546.

Anumba, C.J. \& Ruikar, K. (eds) 2008, e-Business in Construction, Wiley-Blackwell Publishing Ltd, Chichester.

Boyatzis, R.E. 1998, Transforming qualitative information : thematic analysis and code development, Sage, Thousand Oaks, Calif. ; London.

Charoenngam, C., Coquinco, S.T. \& Hadikusumo, B.H.W. 2003, "Web-based application for managing change orders in construction projects.", Construction Innovation, vol. 3, no. 4, pp. 197-215.

Chassiakos, A.P. \& Sakellaropoulos, S.P. 2008, "A web-based system for managing construction information", Advances in Engineering Software, vol. 39, no. 11, pp. 865-876.

Davenport, T.H. (1993), Process Innovation, Harvard Business School Press, Boston, MA.

Dustdar, S. 2005, "Architecture and design of an internetenabled integrated workflow and groupware system", Business Process Management Journal, vol. 11, no. 3, pp. 275290.

Emmitt, S. 2007, "Design Management for Architects, Blackwell Publishing Inc, Malden, MA, USA.

Garimella, K., Lees, M. \& Williams, B. 2008, BPM for Dummies, Wiley Publishing, Inc, Indianapolis, Indiana.

Georgakopoulos, D., Hornick, M. \& Sheth, A. 1995, "An Overview of Workflow Management: From Process Modeling to Workflow Automation Infrastructure", Distributed and Parallel Databases, vol. 3, no. 2, pp. 119-153.

Haymaker, J., Ayaz, E., Fischer, M., Kam, C., Kunz, J., Ramsey, M., Suter, B. \& Toledo, M. 2006, "Managing and communicating information on the Stanford living laboratory feasibility study", ITCon, vol. 11, no. 42, pp. 607-626.

Hegazy, T., Zaneldin, E. \& Grierson, D. 2001, "Improving Design Coordination for Building Projects. I: Information Model", Journal of Construction Engineering and Management, vol. 127, no. 4, pp. 322-329.

Houck, C. 2007, "Breaking through with Business Process Discovery", Business Intelligence Journal, vol. 12, no. 4, pp. 30-39.

Jallow, A.K., Demian, P., Baldwin, A.N. \& Anumba, C.J. 2008, "

Life cycle approach to requirements information management in construction Projects: state-of-the-art and future trends.",

Proceedings of the 24th Annual ARCOM Conference, ed. A. Dainty, Association of Researchers in Construction Management, , pp. 769-778.

Kamara, J.M., Anumba, C.J. \& Evbuomwan, N.F.O. 2002, Capturing client requirements in construction projects, Thomas Telford Ltd, London.

Kamara, J.M. \& Anumba, C.J. 2000, "Client Requirements Processing for Concurrent Life-Cycle Design and Construction", Concurrent Engineering: Research and Applications, vol. 8, no. 2, pp. 74-88.

Karim, A. \& Adeli, H. 1999, "CONSCOM: An OO Construction Scheduling and Change Management System", Journal of Construction Engineering and Management, vol. 125, no. 5, pp. 368-376. 
Khalaf, R., Keller, A. \& Leymann, F. 2006, "Business processes for Web Services: Principles and applications", IBM Systems Journal, vol. 45, no. 2, pp. 425-446.

Kidd, M.W. \& Thompson, G. 2000, "Engineering design change management", Integrated Manufacturing Systems, vol. 11, no. 1, pp. 74-77.

Kirchmer, M. 2009, High Performance Through Process Performance: From Strategy to Operations, Springer-Verlag, Berlin.

Lazarus, D. \& Clifton, R. 2001, Managing project change: A best practice guide, C556 edn, CIRIA, London.

Motawa, I.A., Anumba, C.J., Lee, S. \& Pena-Mora, F. 2007, "An integrated system for change management in construction", Automation in Construction, vol. 16, no. 3, pp. 368377.

Nadia, B., Gregory, G. \& Vince, T. 2006, "Engineering change request management in a new product development process", European Journal of Innovation Management, vol. 9, no. 1, pp. 5-19.

Sabri, E.H., Gupta, A.P. \& Beitler, M.A. 2007, Purchase Order Management Best Practices: Process, Technology, and Change Management, J. Ross Publishing, Fort Lauderdale.

Shiau, J. \& Wee, H.M. 2008, "A distributed change control workflow for collaborative design network", Computers in Industry, vol. 59, no. 2-3, pp. 119-127.

Sinha, V., Sengupta, B. \& Chandra, S. 2006, Enabling Collaboration in Distributed Requirements Management.

Sun, M., Sexton, M., Aouad, G., Fleming, A., Senaratne, S., Anumba, C., Chung, P., El-Hamalawi, A. \& Motawa, I. 2004, Managing Changes in Construction Projects, MCD Research Project, University of the West of England.

Swenden, W. 2006, Federalism and Regionalism in Western Europe : A Comparative and Thematic Analysis, Palgrave Macmillan, Basingstoke.

Tanrikorur, T. March 2007, Business Process Management 101: The Basics of BPM and How to Choose the Right Suite, CMP Media LLC, NY.

Taylor, L. 2007, Knowledge, Information and the Business process: Revolutionary thinking or Common Sense? Chandos Publishing, Oxford, UK.

Wilkinson, P. 2005, Construction Collaboration Technologies: The Extranet Evolution, Taylor and Francis, Abingdon, Oxon, UK.

Yan, X., Eynard, B. \& Ion, W. (eds) 2008, Global design to Gain a Competitive Edge: A Holistic and Collaborative Design Approach based on Computational Tools, SpringerVerlag, London. 